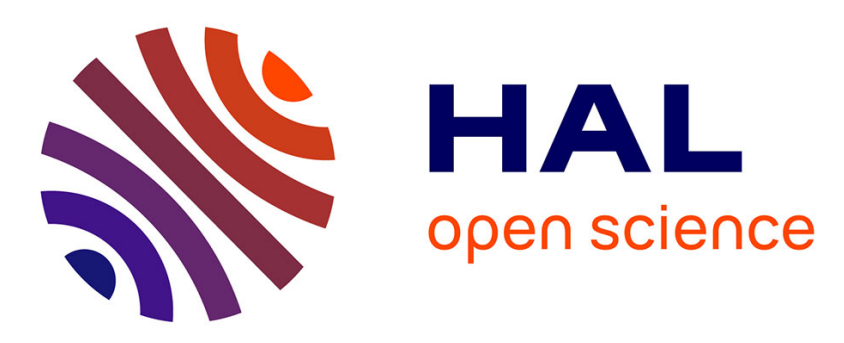

\title{
Chirping techniques for enhancing the performance of SOA-based UWB over fiber systems: An experimental demonstration
}

Haidar Taki, Stéphane Azou, Ali Hamie, Pascal Morel, Ali Al Housseini, Ali Alaeddine, Ammar Sharaiha

\section{To cite this version:}

Haidar Taki, Stéphane Azou, Ali Hamie, Pascal Morel, Ali Al Housseini, et al.. Chirping techniques for enhancing the performance of SOA-based UWB over fiber systems: An experimental demonstration. AEÜ - International Journal of Electronics and Communications / Archiv für Elektronik und Übertragungstechnik, 2018, 94, pp.221 - 225. 10.1016/j.aeue.2018.07.008 . hal-01858825

\section{HAL Id: hal-01858825 \\ https://hal.science/hal-01858825}

Submitted on 21 Aug 2018

HAL is a multi-disciplinary open access archive for the deposit and dissemination of scientific research documents, whether they are published or not. The documents may come from teaching and research institutions in France or abroad, or from public or private research centers.
L'archive ouverte pluridisciplinaire HAL, est destinée au dépôt et à la diffusion de documents scientifiques de niveau recherche, publiés ou non, émanant des établissements d'enseignement et de recherche français ou étrangers, des laboratoires publics ou privés. 
H. Taki, S. Azou, A. Hamie, P. Morel, A. Al Housseini, A. Alaeddine, and A. Sharaiha, "Chirping Techniques for Enhancing the Performance of SOA-based UWB over Fiber Systems: An Experimental Demonstration", Elsevier AEÜ - International Journal of Electronics and Communications, 94, pp. 221-225, 2018.

\title{
Chirping Techniques for Enhancing the Performance of SOA-based UWB over Fiber Systems: An Experimental Demonstration
}

\author{
Haidar Taki ${ }^{a}$, Stéphane Azou ${ }^{b, *}$, Ali Hamie ${ }^{c}$, Pascal Morel ${ }^{b}$, Ali Al \\ Housseini $^{a}$, Ali Alaeddine ${ }^{a}$, and Ammar Sharaiha ${ }^{b}$ \\ ${ }^{a}$ Lebanese University, Faculty of Science I, LPE research center, Beirut, Lebanon \\ ${ }^{b}$ ENIB / CNRS UMR 6285 Lab-STICC, Brest, France \\ ${ }^{c}$ CRITC research center, Arts Sciences and Technology University in Lebanon (AUL) \\ *Corresponding author,Email: azou@enib.fr
}

\begin{abstract}
A phaser-based processing technique was adopted in an UWB over fiber system employing SOA. The target is to simultaneously reduce the ASE noise impact and nonlinear effects inherent to optical amplification. Experimental results prove the effectiveness of chirping in terms of cross correlation and bit error rate.

Keywords: Ultra WideBand (UWB), Radio-over-fiber (RoF), Chirping, Semiconductor Optical Amplifier (SOA), Nonlinearity, Amplified Spontaneous Emission (ASE).
\end{abstract}

\section{Introduction}

The increasing demand for high speed and low power transmission systems nowadays, increases the attention towards ultra wideband (UWB) radio technology, which is a promising solution for new generations of short-range broadband wireless communications [1, 2, 3]. UWB was born in 2002, when the Federal Communication Commission (FCC) approved its free space propagation within a $7.5 \mathrm{GHz}$ band and $-41.3 \mathrm{dBm} / \mathrm{MHz}$ maximum emitted power [1]. UWB over fiber has known a growing interest over the past decade, as by exploiting the benefits of optical link a high quality of transmission may be achieved at long distances [4]. A particular scenario of UWB is the 
Impulse Radio, which is a cost effective approach offering a low order of generation complexity [5] together with a simple design at the receiver side if a non-coherent detection is adopted [6]. With the view to get a reach extension in the optical access network, a low cost Semiconductor Optical Amplifier (SOA) has been recently employed [7, 8]. However, a performance degradation may occur due to the nonlinear effects and Amplified Spontaneous Emission (ASE) noise inherent to SOA. In [8], we have overcome these two impairments via phaser-based processing techniques [9], a significant improvement in the power efficiency and bit error rate has been carried out, due to symmetrical up and down chirping performed at the transmitter and receiver respectively. The key concept is that a lower order of four wave mixing and cross gain modulation is obtained against signals with less frequency diversity. A special effort is applied here to experimentally demonstrate the effectiveness of chirping in a practically implemented UWB over fiber system. Considering On Off Keying (OOK) and Pulse Position Modulation (PPM) formats, a better signal quality is achieved, and a lower number of errors are collected at receiver side, thanks to chirping.

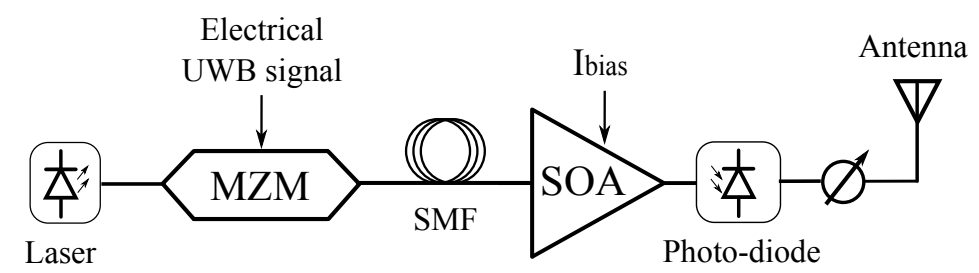

Figure 1: Block diagram of the basic Radio over Fiber system.

\section{UWB over fiber system architecture and experimental setup}

Figure 1 describes our basic radio over fiber system, the transmitter relies on a Mach-Zehnder Modulator (MZM) with half-wave voltage $V_{\pi}$ of $6 \mathrm{~V}$, biased at $V_{D C}=1.5 V_{\pi}$ by the electrical UWB signal, and with a continuous wave light at its input. The channel is made of a Single Mode Fiber (SMF) with a use of SOA for pre-amplification purpose. There is a growing interest for designing preamplified optical integrated receivers, and the SOA is a pertinent solution for such applications due to its low cost and complexity $[10,11]$. At the receiver side, a photo-detector converts the optical power into an electrical voltage signal, the latter being attenuated before entering the antenna so as to meet FCC mask. The experimental setup is stated 
in fig. 2, the transmitter relies on the Agilent Arbitrary Waveform Generator (AWG - M8190A), which electrically generates the signals designed in MatlaB, where the sampling frequency is $12 \mathrm{GHz}$ and the maximum produced voltage is $700 \mathrm{mV}$. A radio frequency amplifier (SHF Communication Technologies AG - 115 BP) has been placed so as to boost the driving voltage entering the single arm MZM (Photline Technologies). On the optical source side, the laser diode has a fixed power of $12 \mathrm{dBm}$, which can be tuned via Attenuator (JDS Uniphase) before being injected to MZM. Then, the optical field propagates over $40 \mathrm{~km}$ of single mode fiber with a $0.2 \mathrm{~dB} / \mathrm{km}$ attenuation and a dispersion coefficient of $17 \mathrm{ps} / \mathrm{nm} / \mathrm{km}$, to finally reach the SOA (Inphenix-IPSAD1581). The central wavelength of the optical filter (XTM-50) after SOA is $1540 \mathrm{~nm}$, which corresponds to that at the laser output, and the $10 \mathrm{~dB}$ bandwidth is $30 \mathrm{pm}$. A periodic observation for the spectrum and average power is mandatory in order to re-calibrate the polarization controller after any systematical change in the fiber characteristics, as the latter are highly affected by the physical conditions of the surrounding environment; hence, an Optical Spectrum Analyzer (OSA - ADVANTEST Q8384) has been placed for that purpose. The photo-detector (HEWLETT PACKARD 11982A), with $15 \mathrm{GHz}$ bandwidth, converts the optical field into an electrical voltage signal to be ready for entering the oscilloscope. Finally, the received waveform is sampled at $\mathrm{Fs}=40 \mathrm{GHz}$, then saved for post processing in MATLAB.

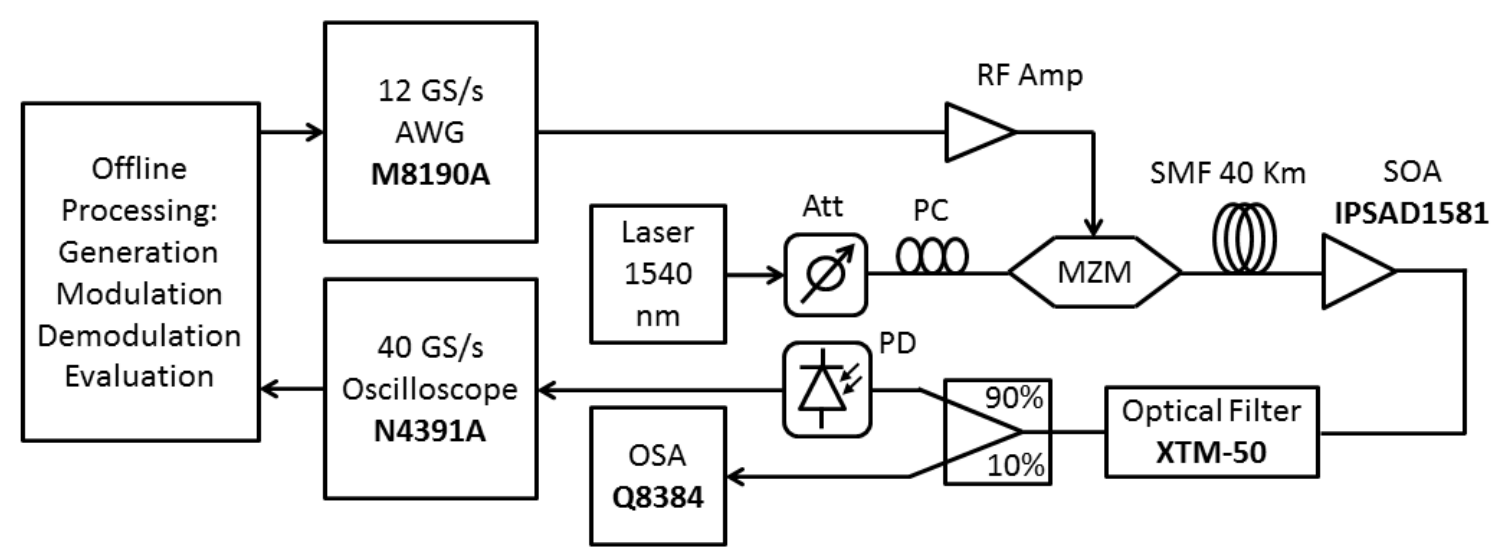

Figure 2: A schematic diagram for the experimental setup, (Amp: Amplifier, MZM: Mach-Zehnder Modulator, SMF: Single Mode Fiber, SOA: Semiconductor Optical Amplifier, Att: Attenuator, PC: Polarization Controller, PD: Photo-detector). 


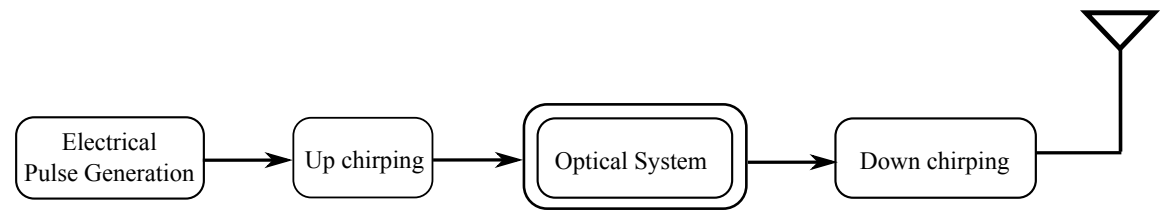

Figure 3: Up and down chirping applied before and after the optical system respectively, which includes the MZM, fiber, SOA, and photo-detector.

\section{Performance evaluation of phaser-based UWB over fiber system}

The block diagram of the proposed system is described in fig. 3, with up and down chirping taking place before and after the optical system respectively. The chirping-based transmission concept was initially explored by Nikfal [9], who has succeeded in enhancing the signal-to-noise ratio of the impulse radio transceiver using phasers. The latter have dispersive structures with a controllable group delay [12], which apply linear up or down chirping to stretch or compress the input signal without changing the total energy. So if the pulse is elongated by a time spread of $M$, the average power will be reduced by the same factor $M$. The transmitter operates a linear up chirping for the data signals before entering the channel, while down chirping with an absolutely equal slope is performed at receiver side, so the instantaneous frequencies are equalized and the signal is compressed to an enhanced waveform that exactly matches the original [9]. The time and frequency domain expressions of the chirped signal are described in equations (1), (2), and (3), besides to the frequency dependent time delay function $\tau(f)$. The original pulse is $x(t), a$ is the chirping slope (which is positive for up chirping and negative for down chirping), where $b$ is the delay offset. Equation (3) informs that chirping affects only the phase of the spectrum without varying its magnitude, hence it has no influence on the power spectral density.

$$
\begin{gathered}
y(t)=x(t+\tau(f)) \\
\tau(f)=a f+b \\
Y(f)=X(f) \exp (2 \pi f \tau(f) j)=X(f) \exp \left(2 \pi a f^{2} j\right) \exp (2 \pi f b j)
\end{gathered}
$$

Chirping scheme has shown to be effective in our previous simulations, a very good power efficiencies being obtained for the $5^{\text {th }}$ Gaussian pulse besides to Abraha's combination of Doublets [8]. Here we examine the potential of chirping in a real SOA-based optical system so as to confirm the effectiveness 

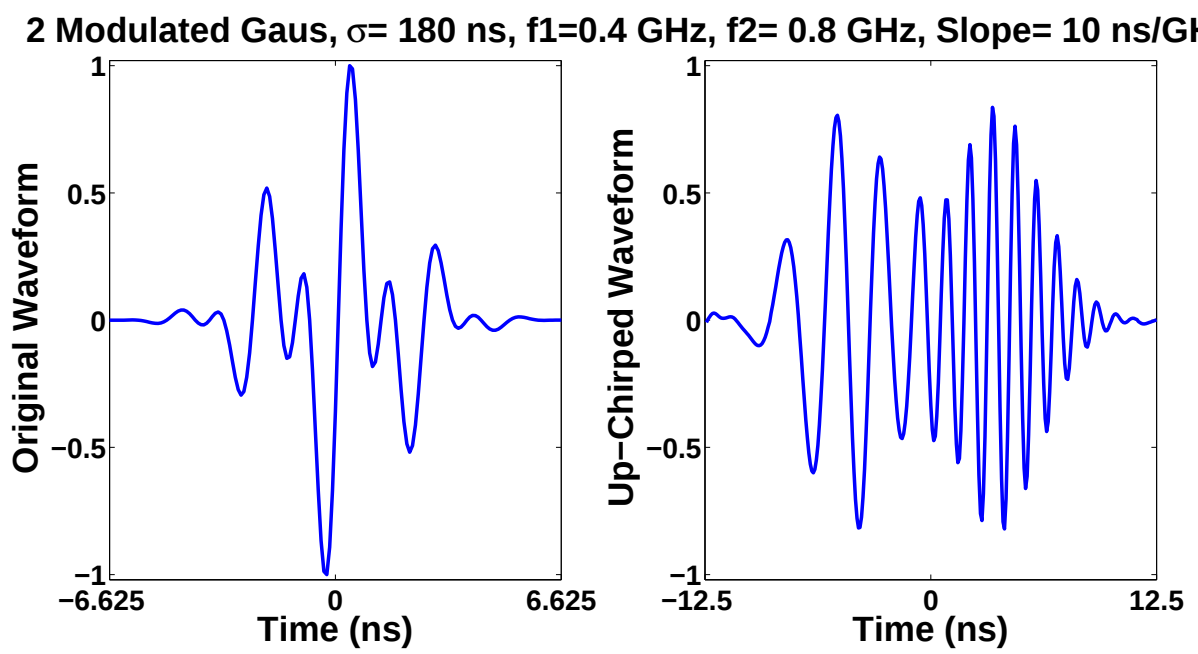

Figure 4: Time waveforms of the original (left) and up-chirped (right) combination of modulated Gaussians in electrical domain, where $\sigma=180 \mathrm{~ns}, f_{1}=0.4 \mathrm{GHz}, f_{2}=0.8$ $\mathrm{GHz}$, and the slope is $10 \mathrm{~ns} / \mathrm{GHz}$.

of this scheme, while up/down chirping is performed in offline processing via simple phaser models in MATLAB. Due to the band limitation of the AWG used, it was not possible to generate the same waveforms as in [8], on the other side, dealing with pulses having a frequency diversity is much easier to see the benefits of chirping. Therefore, we have proposed a combination of 2 modulated basic Gaussians $g_{1}$ and $g_{2}$, with different carrier frequencies $f_{1}$ and $f_{2}$, in order to see the original signal as two overlapped waveforms which could be separated via chirping. It is preferred to absolutely separate $g_{1}$ from $g_{2}$, in order to get a better readability and more accurate evaluation while comparing with the non-chirped signal, that is provided when satisfying the condition $f_{2} \geq f_{1}$. The time duration of the utilized combination is $13.25 \mathrm{~ns}$, where the pulse shaping factor for both Gaussians is $\sigma=180$ ns. For such a pulse period and spreading factor, $f_{1}=0.4 \mathrm{GHz}$ and $f_{2}=0.8 \mathrm{GHz}$ are good candidate frequencies which fit our target. Figure 4 shows the non-chirped (a) and chirped (b) signals, the time duration of the latter is $25 \mathrm{~ns}$, which is slightly less than double the original, with a chirping slope of $10 \mathrm{~ns} / \mathrm{GHz}$. As clearly noticed, the left and right portions of the chirped waveform have the same time behavior but different modulation frequencies. From fig. 5 we can observe the better correlation between the received and transmitted waveforms when chirping is adopted, as a lower order of SOA nonlinearity 


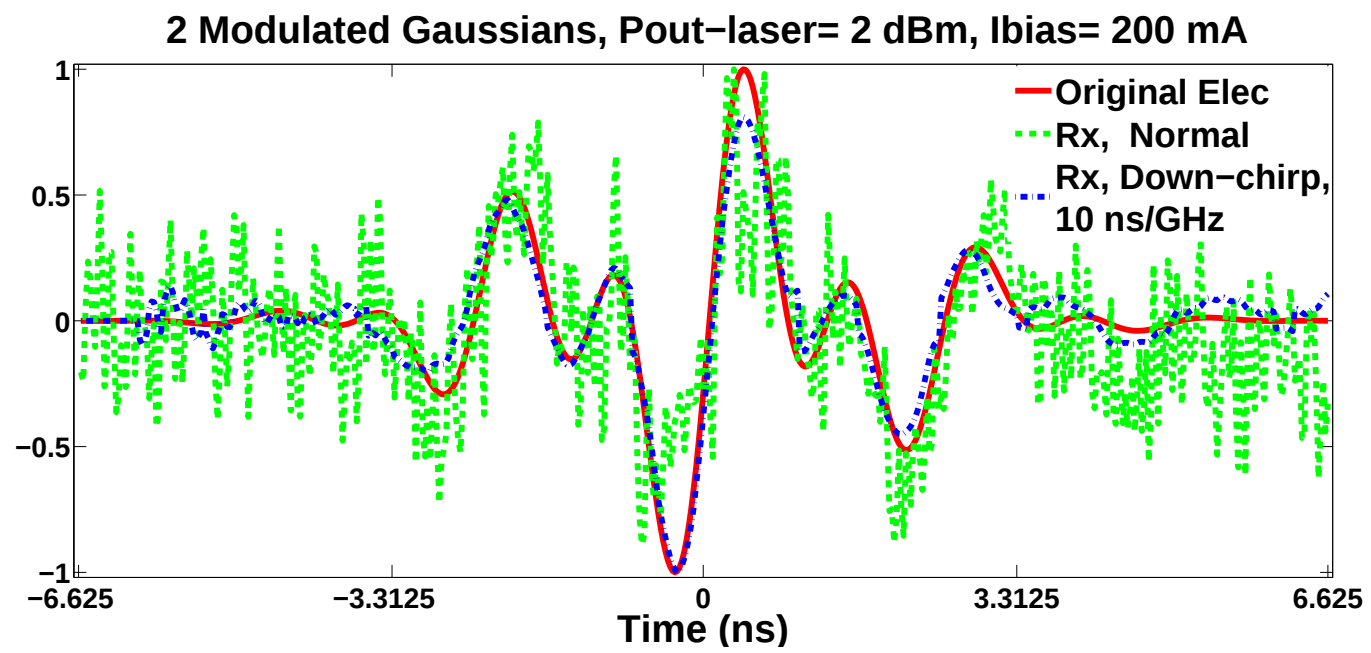

Figure 5: The time waveforms of the received pulse with and without chirping (at a slope of $10 \mathrm{~ns} / \mathrm{GHz}$ ) besides to the original pulse in electrical domain, the laser output power is $2 \mathrm{dBm}$ and $I_{\text {bias }}=200 \mathrm{~mA}$.

is associated to chirped waveforms, while the amplifier input power is -21 $\mathrm{dBm}$. Moreover, a higher signal-to-noise ratio is achieved, promising for an improvement in the bit error rate performance.

$$
X C T E R=\frac{\operatorname{Max}\left\{x_{T}(t) \star x_{R}(t)\right\}}{\int_{-T / 2}^{+T / 2} x_{R}^{2}(t) d t}
$$

The cross correlation to energy ratio (XCTER) between the electrically generated pulse $x_{T}(t)$ and received one $x_{R}(t)$ after the photo-detector is expressed in eq. (4), this criteria is useful for evaluating the potential of chirping in mitigating SOA nonlinearities. XCTER has been studied versus the laser output power in fig. 6 considering $I_{\text {bias }}=100 \mathrm{~mA}$ and $I_{\text {bias }}=200 \mathrm{~mA}$ with 10 $\mathrm{ns} / \mathrm{GHz}$ chirping slope, the increasing response for different settings is due to the raise in the optical signal-to-noise ratio (OSNR). At negative powers, we can see a crossing between the dashed curves for the non-chirped pulses, that is due to the higher degree of linearity obtained at low SOA input powers, so the linearity gain associated with decreasing the biasing current appears when the OSNR becomes extremely low. That's why the chirped waveforms achieve a better correlation in all conditions, since chirping mitigate the SOA nonlinearities and reduce the ASE noise impact simultaneously. In terms of bit error rate (BER) performance, fig. 7 illustrates the effectiveness of 


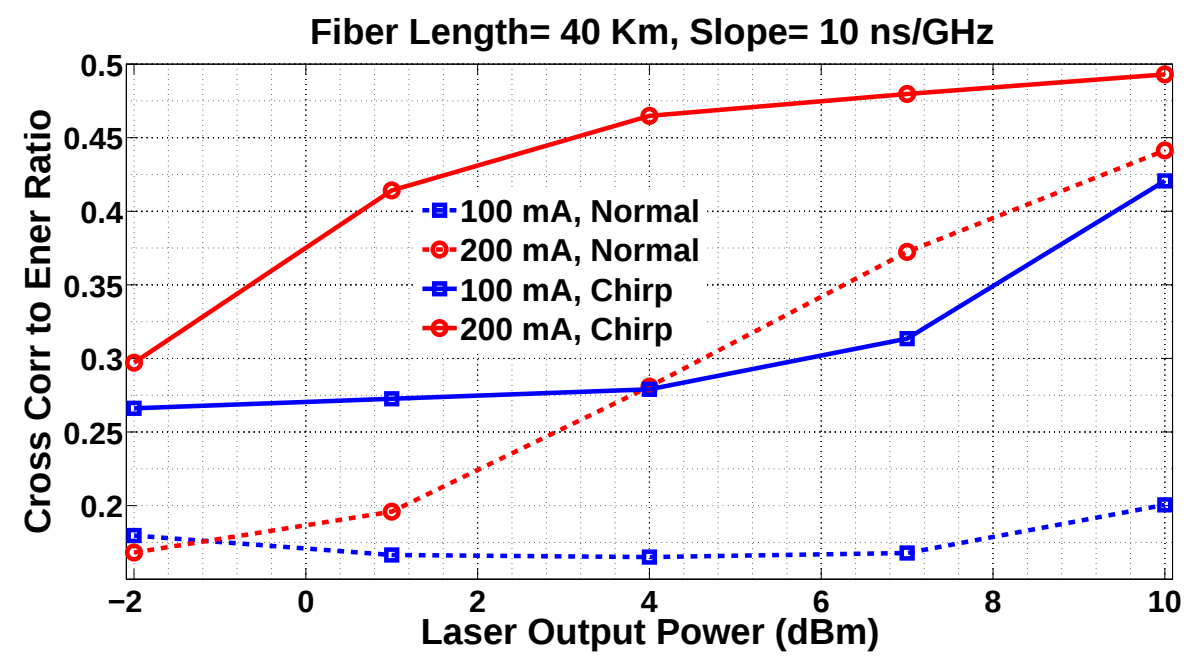

Figure 6: Cross correlation to energy ratio versus laser output power for $I_{\text {bias }}=100 \mathrm{~mA}$ and $I_{\text {bias }}=200 \mathrm{~mA}$, the chirping slope is $10 \mathrm{~ns} / \mathrm{GHz}$.

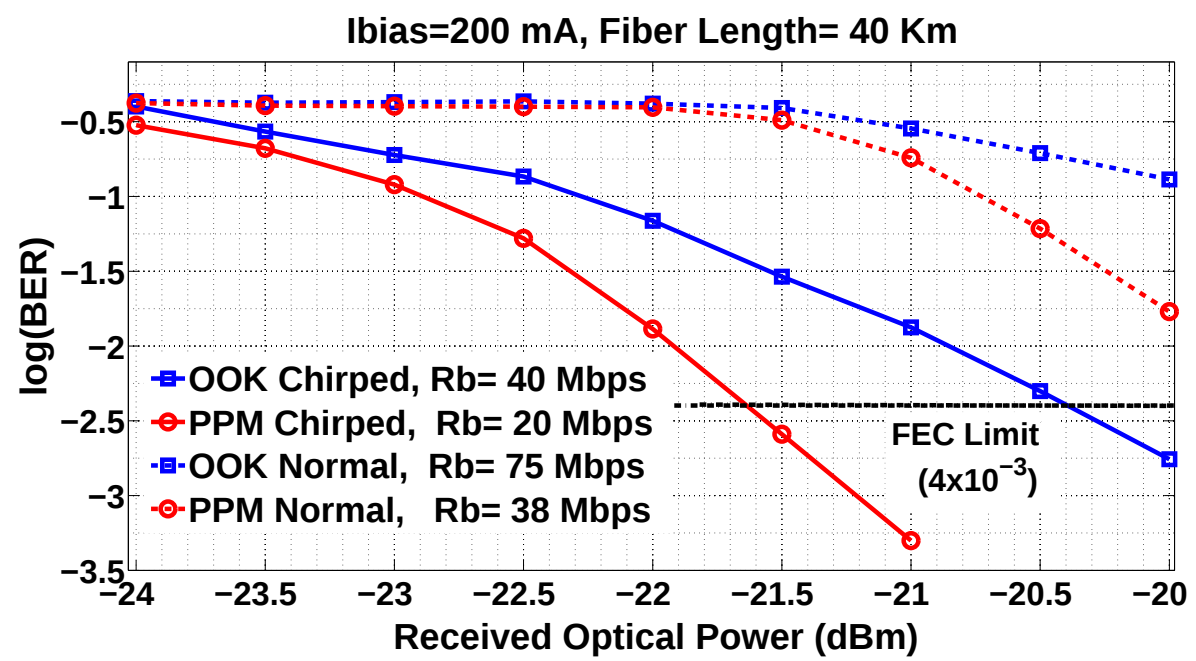

Figure 7: Bit error rate versus received optical power for chirped and non-chirped OOK and PPM modulation schemes, where $I_{\text {bias }}=200 \mathrm{~mA}$.

chirping with OOK and PPM modulation formats; the chirped transmission outperforms the classical one for different values of received optical power. Detecting the PPM symbols is based on comparing the two time slots energies in each frame; where for OOK, the threshold for data decision in each iteration is computed by estimating the average energy per bit from the total 
received energy (which corresponds to the overall stream of pulses). Therefore, nonlinearity has no great influence on the BER of such non-coherent scenarios, as the cross gain modulation and four wave mixing are deterministic for a fixed SOA operating point. The collected errors are mainly due to ASE, in addition to the inherent noises produced by the other optical and electrical components in our system. The potential of chirping has been proved in simulations while operating at 1 Gbps data rate [8], which was not possible to reach experimentally due to the band limitation of our AWG. In fact, tens Mbps is not an extremely low bit rate for UWB communications, as reported in the literature [13]. The probability of error is within the forward error correction (FEC) limit, where SOA is placed at $40 \mathrm{~km}$ and injected by $200 \mathrm{~mA}$ biasing current. A portion of the received OOK

Received OOK at $40 \mathrm{Km}, 200 \mathrm{~mA}$, slope $=10 \mathrm{~ns} / \mathrm{GHz}, \mathrm{P}$-laser $=3 \mathrm{dBm}$
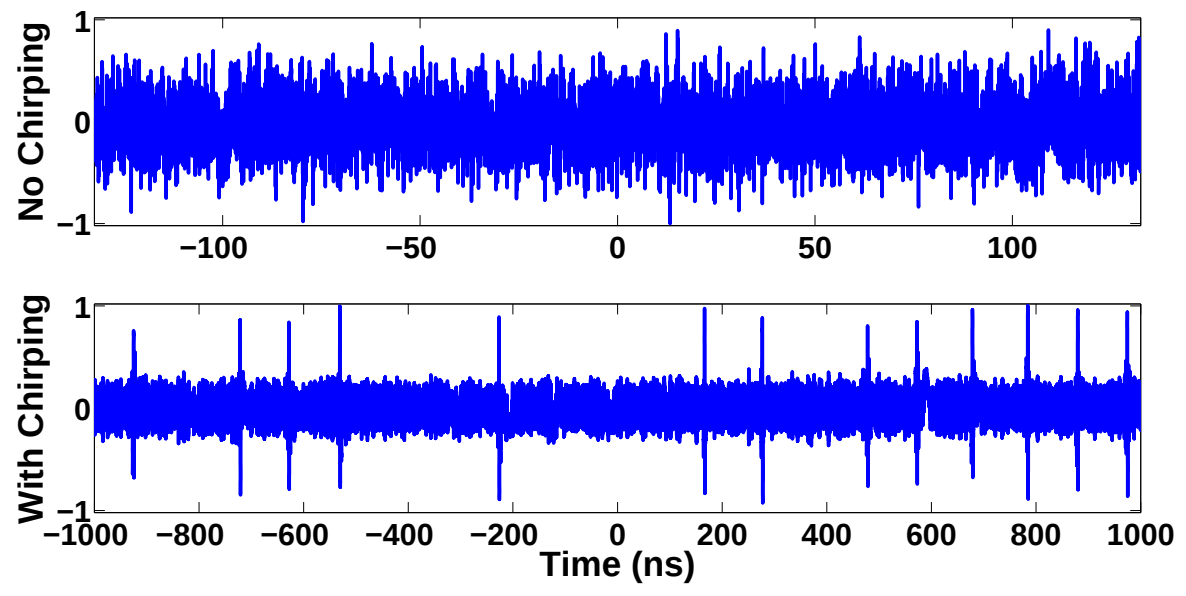

Figure 8: Received OOK just after SOA (at $40 \mathrm{~km}$ ) in the case of no chirping (up) and chirping (down) with a slope of $10 \mathrm{~ns} / \mathrm{GHz}$, where the laser output power is $3 \mathrm{dBm}$ and $I_{\text {bias }}=200 \mathrm{~mA}$.

signal is plotted in fig. 8 with (down) and without (up) chirping, these time waveforms clearly exhibit the enhancement in the BER performance, as the signal-to-noise ratio rises at the receiver side. The benefits of chirping are not limited to SOA, it is a general approach which could be applied in nonlinear and noisy systems; however, the earnings of this scheme are constrained by the physical characteristics as well as the operating conditions of electrical or optical components. 


\section{Conclusion}

We experimentally demonstrated the effectiveness of some chirping techniques for both linearizing SOA characteristics and reducing ASE noise influence in an UWB over fiber system. Higher cross correlation between transmitted and received pulses was achieved, besides to a lower BER obtained with OOK and PPM modulations. Our approach is not restricted to SOA, as chirping offers a processing gain which may cope with various microwavephotonics system impairments. Some performance gain may be expected also for other kind of power amplifiers including EDFA. Note however that each setup requires a specific study with closely related phaser design.

\section{References}

[1] Ghavami, M., Michael, L., and Khono, R., Ultra Wideband Signals and Systems in Communication Engineering, John Wiley and Sons, 2007.

[2] Aiello, G.R., Rogerson, G.D., Ultra-wideband wireless systems, IEEE Microwave Mag. 4 (2) (2003) 36-47.

[3] V. Niemelä, J. Haapola, M. Hämäläinen and J. Iinatti, "An Ultra Wideband Survey: Global Regulations and Impulse Radio Research Based on Standards," IEEE Communications Surveys \& Tutorials, vol. 19, no. 2, pp. 874-890, Secondquarter 2017.

[4] Pan, S., Yao, J. (2010). UWB-over-fiber communications: modulation and transmission. Journal of Lightwave Technology, 28(16), 2445-2455.

[5] Win, M. Z., Scholtz, R. A. (2000). Ultra-wide bandwidth time-hopping spread spectrum impulse radio for wireless multiple-access communications. IEEE Transactions on communications, 48(4), 679-689.

[6] Hafiz M., Sasaki N., Kikkawa T., A 800 Mb/s CMOS detection scheme for UWB impulse-radio communication, Int. J. Electron. Commun. (AË̈), 65, pp. 398-405, 2011.

[7] Taki, H., Azou, S., Hamie, A., Al Housseini, A., Alaeddine, A., and Sharaiha, A. (2017). Simple pre-distortion schemes for improving the 
power efficiency of SOA-based IR-UWB over fiber systems. Optics communications, 382, 225-231.

[8] Taki, H., Azou, S., Hamie, A., Al Housseini, A., Alaeddine, A., and Sharaiha, A. (2017). On phaser-based processing of impulse radio UWB over fiber systems employing SOA. Optical Fiber Technology, 36, 33-40.

[9] Nikfal, B., Zhang, Q., and Caloz, C. (2014). Enhanced-SNR impulse radio transceiver based on phasers. IEEE Microwave and Wireless Components Letters, 24(11), 778-780.

[10] Caillaud, C., Chanclou, P., Blache, F., Angelini, P., Duval, B., Charbonnier, P., ... and Achouche, M. (2015). Integrated SOA-PIN detector for high-speed short reach applications. Journal of Lightwave Technology, 33(8), 1596-1601.

[11] Caillaud, C., Glastre, G., Lelarge, F., Brenot, R., Bellini, S., Paret, J. F., ... and Achouche, M. (2012). Monolithic integration of a semiconductor optical amplifier and a high-speed photodiode with low polarization dependence loss. IEEE Photonics Technology Letters, 24(11), 897-899.

[12] Q. Zhang, D.L. Sounas, C. Caloz, Synthesis of cross-coupled reducedorder dispersive delay structures (DDSs) with arbitrary group delay and controlled magnitude, IEEE Trans. Microwave Theory Tech. 61 (3) (2013) 1043-1052.

[13] Ryckaert, J., Verhelst, M., Badaroglu, M., D’Amico, S., De Heyn, V., Desset, C., ... and Dehaene, W. (2007). A CMOS ultra-wideband receiver for low data-rate communication. IEEE Journal of Solid-State Circuits, $42(11), 2515-2527$. 